\title{
Community-acquired Serratia marcescens spinal epidural abscess in a patient without risk factors: Case report and review
}

\author{
Michael D Parkins MD FRCPC ${ }^{1}$, Daniel B Gregson MD FRCPC $1,2,3$
}

\begin{abstract}
MD Parkins, DB Gregson. Community-acquired Serratia marcescens spinal epidural abscess in a patient without risk factors: Case report and review. Can J Infect Dis Med Microbiol 2008;19(3):250-252.

Serratia marcescens has rarely been reported as an agent of invasive disease in patients presenting from the community. Furthermore, $S$ marcescens is frequently opportunistic, affecting individuals with serious medical comorbidities including immune suppression and diabetes. A case of a community-acquired $S$ marcescens spontaneous lumbar epidural abscess presenting as cauda equina syndrome is reported in a previously well 36-year-old man with no identifiable risk factors. To the authors' knowledge, this is the first report of invasive $S$ marcescens causing disease in a patient with no medical comorbidities.
\end{abstract}

Key Words: Community-acquired; Immunocompetent; Invasive; Serratia marcescens; Spinal epidural abscess

\section{Un abcès spinal épidural à Serratia marcescens non nosocomial chez un patient sans facteur de risque : Rapport de cas et analyse}

\begin{abstract}
On a rarement déclaré des cas de Serratia marcescens comme agent de maladie envahissante chez des patients provenant de la collectivité. De plus, le $S$ marcescens est souvent opportuniste, touchant des personnes atteintes de graves comorbidités médicales, y compris l'immunosuppression et le diabète. Un cas d'abcès lombaire épidural spontané à $S$ marcescens non nosocomial se manifestant sous forme de syndrome de la queue de cheval est déclaré chez un homme de 36 ans auparavant en santé, sans facteur de risque dépistable. Pour autant que le sache l'auteur, c'est le premier rapport de maladie provoquant un $S$ marcescens envahissant chez un patient n'ayant pas de comorbidités médicales.
\end{abstract}

Serratia marcescens is an aerobic, motile, Gram-negative Sacillus that is well-recognized as a pathogen in nosocomial settings. One area in which there appears to be a predilection for infection is in postoperative central nervous system (CNS) infections (1). Although rare, $S$ marcescens can cause disease in the community, primarily in immunocompromised hosts and illicit drug users (2). A case of a spontaneous communityacquired spinal epidural abscess (SEA) is reported in a previously well 36-year-old man presenting with cauda equina syndrome.

\section{CASE PRESENTATION}

A 36-year-old man was admitted to hospital because of fever, back and leg pain, and urinary retention. He had been unwell for seven days before admission, but he could not associate symptom onset with any inciting event. The patient worked as a computer programmer and was previously well, with the exception of chronic back pain, which was attributed to sports injuries, a remote laparoscopic cholecystectomy and remote bilateral meniscal repairs. The patient denied illicit drug use or risk factors for HIV. On admission, his temperature was $38.7^{\circ} \mathrm{C}$, pulse rate 87 beats $/ \mathrm{min}$ and blood pressure $129 / 81 \mathrm{mmHg}$. His neurological examination was remarkable only for diminished ankle reflexes with normal plantar responses, saddle anesthesia, reduced rectal tone and a distended bladder. The patient's cardiopulmonary and abdominal examinations were otherwise unremarkable. There was a notable absence of evidence of soft tissue infection, stigmata of infectious endocarditis or track marks.

Routine laboratory tests were normal, with the exception of neutrophilia $\left(13.2 \times 10^{9} / \mathrm{L}\right)$ and an elevated erythrocyte sedimentation rate $(35 \mathrm{~mm} / \mathrm{h})$. His blood chemistry, liver function tests and urinalysis were normal. A magnetic resonance imaging (MRI) scan showed impingement of the nerve roots at L4-L5 and L5-S1, but there was no clear collection suggestive of epidural abscess or discitis. The patient was given a single dose of trimethoprim/sulfamethoxazole for a presumed urinary tract infection as cause of fever, despite a normal urinalysis, and was immediately taken to the operating room for a presumed disc herniation. At procedure, frank pus and granulation tissue were evident at L4-S1. An L5-S1 laminectomy was performed after irrigation and debridement. There was no intraoperative evidence of osteomyelitis. Intraoperative cultures and blood cultures were positive at $24 \mathrm{~h}$ for nonpigmented $S$ marcescens. The patient did not receive empirical antibiotic therapy for a SEA until the surgical diagnosis was made $18 \mathrm{~h}$ after presentation; he was then started on $2 \mathrm{~g}$ ceftriaxone given intravenously every $12 \mathrm{~h}$ and $1 \mathrm{~g}$ vancomycin given intravenously every $12 \mathrm{~h}$. Once the species was identified, antibiotics were corrected to $2 \mathrm{~g}$ meropenem given intravenously every $8 \mathrm{~h}$. The patient was discharged after seven days on $1 \mathrm{~g}$ ertapenem taken intravenously every $24 \mathrm{~h}$ and $500 \mathrm{mg}$ ciprofloxacin taken orally twice per day for six weeks. Dual-agent therapy was prolonged a further

\footnotetext{
${ }^{1}$ Departments of Medicine; ${ }^{2}$ Pathology and Laboratory Medicine, University of Calgary, ${ }^{3}$ Calgary Laboratory Services, Calgary, Alberta Correspondence: Dr Daniel B Gregson, Division of Microbiology, Calgary Laboratory Services, 9-3535 Research Road Northwest, Calgary,

Alberta T2L 2K8. Telephone 403-770-3309, fax 403-770-3347, e-mail Dan.Gregson@CLS.ab.ca

Received for publication August 15, 2007. Accepted January 5, 2008
} 

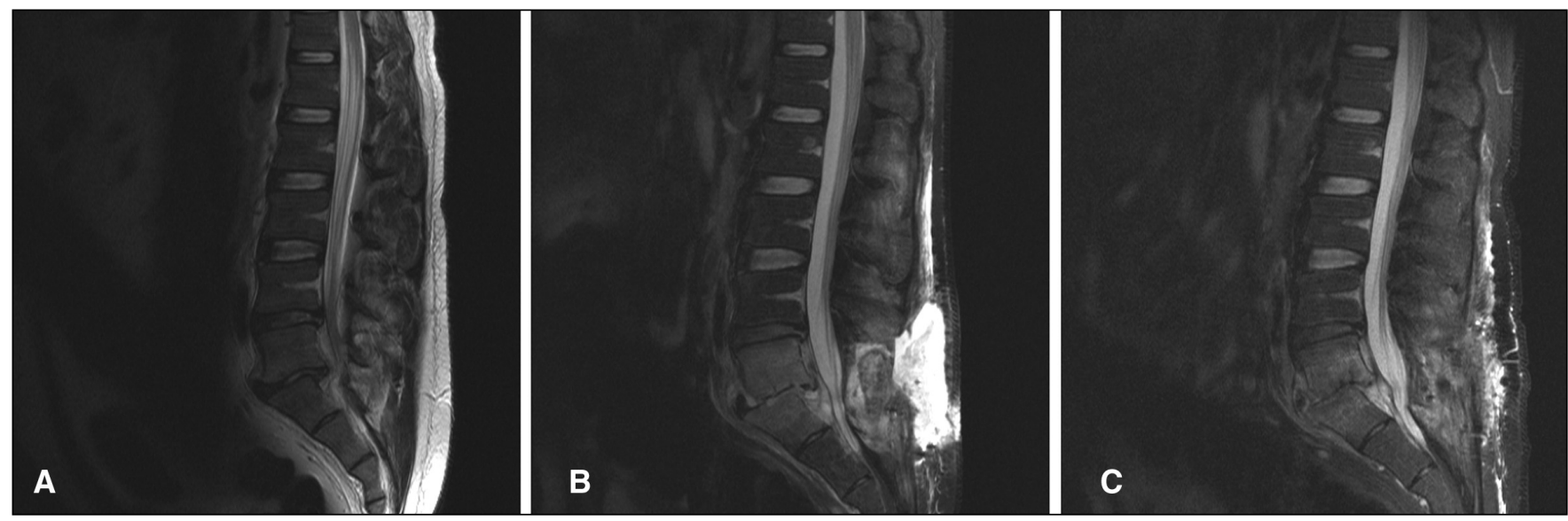

Figure 1) Serial T2-weighted magnetic resonance imaging scans of the lumbar spine before and during treatment showing progression and resolution of fluid collection ( $\mathrm{A}$ - day 0 , preoperative; $\mathbf{B}$ - day 35; $\mathbf{C}$ - day 78)

six weeks because of persistent fluid collection and progression of disease on reimaging (Figure 1). The patient regained full neurological function and was back to baseline clinical status within two weeks following postdischarge.

\section{DISCUSSION}

SEA is a rare event, comprising 0.2 to two cases per 10,000 hospital admission (3). SEA is associated with a mortality of $15 \%$. Risk factors identified include surgical manipulation, distal site of infection, trauma, immune suppression, diabetes, renal failure and illicit parenteral drug abuse (3). Gram-negative bacteria are identified as causative organisms in fewer than $5 \%$ of cases. Spontaneous SEA in the absence of these risk factors represents fewer than $5 \%$ to $20 \%$ of occurrences $(3,4)$. While neuroimaging may be an important tool in identifying and managing cases, its sensitivity is only $90 \%$ overall; acute cases are more likely to be unrecognized, as illustrated by the present case (3).

Using MEDLINE, we searched the English literature from 1966 to June 2007 for similar presentations. The terms searched included 'Serratia' combined with 'invasive', 'abscess', 'epidural', 'spontaneous', 'community' and 'immunocompetent'. All articles had their references reviewed for inclusion. While $S$ marcescens has not previously been reported to cause isolated SEA, it has been associated with CNS disease in various postsurgical forms, including osteomyelitis, spondylodiscitis, meningitis, brain and epidural abscesses $(1,5)$, and secondary spread from other areas of infection (6). S marcescens spinal infection is associated with a mortality of greater than $50 \%$, despite adequate recognition and treatment (1).

\section{REFERENCES}

1. Huang CR, Lu CH, Chien CC, Chang WN. Protean infectious types and frequent association with neurosurgical procedures in adult Serratia marcescens CNS infections: Report of two cases and review of the literature. Clin Neurol Neurosurg 2001;103:171-4.

2. Yu VL. Serratia marcescens: Historical perspective and clinical review. N Engl J Med 1979;300:887-93.

3. Reihsaus E, Waldbaur H, Seeling W. Spinal epidural abscess: A meta-analysis of 915 patients. Neurosurg Rev 2000;23:175-204; discussion 205.
Risk factors for the acquisition of $S$ marcescens infection include immune suppression, diabetes, renal failure, steroid use and malignancy (7). Community occurrences have commonly been associated with contaminated depot, parenteral solutions (8) and illicit drug use (9). Invasive $S$ marcescens infection from the community has been reported in several circumstances, including late-onset post-traumatic meningitis (10), fistulizing Crohn's disease (6), septic abortion and chorioamnionitis (11). In each instance of community-acquired invasive disease identified in the literature, an inciting event or risk factor could be identified. The present case is unique, given the notable absence of risk factors and the relatively rare clinical presentation.

The advent of MRI has greatly aided in the diagnosis and management of spinal cord impingement syndromes. However, over-reliance on MRI modalities can result in an inappropriate false-negative diagnosis in $10 \%$ of cases (3). Although uncommon as a cause of cauda equina syndrome in previously well individuals, bacterial SEA is an important component of the differential of this presentation owing to its high morbidity and mortality. In patients presenting with cauda equina syndrome with fever, leukocytosis and elevated inflammatory markers, SEA should remain a diagnosis of exclusion to be determined postoperatively. Aggressive treatment with early surgical decompression and targeted empirical antimicrobials with adequate $\mathrm{CNS}$ penetration are vital to minimizing neurological sequelae. Due to the increasing prevalence of AmpC- (12) and extended-spectrum beta-lactamase- $(13,14)$ producing coliforms in the community, we suggest using a fluoroquinolone or carbapenem in conjunction with antistaphylococcal therapy pending the identification of the causal agent in this condition.

4. Darouiche RO, Hamill RJ, Greenberg SB, Weathers SW, Musher DM. Bacterial spinal epidural abscess. Review of 43 cases and literature survey. Medicine (Baltimore) 1992; 71:369-85.

5. Hadjipavlou AG, Gaitanis IN, Papadopoulos CA, Katonis PG, Kontakis GM. Serratia spondylodiscitis after elective lumbar spine surgery: A report of two cases. Spine 2002;27:E507-12.

6. Heidemann J, Spinelli KS, Otterson MF, Binion DG. Case report: Magnetic resonance imaging in the diagnosis of epidural abscess 
complicating perirectal fistulizing Crohn's disease. Inflamm Bowel Dis 2003;9:122-4.

7. Bouza E, García de la Torre M, Erice A, Cercenado E, Loza E, Rodríguez-Créixems M. Serratia bacteremia. Diagn Microbiol Infect Dis 1987;7:237-47.

8. Civen R, Vugia DJ, Alexander R, et al. Outbreak of Serratia marcescens infections following injection of betamethasone compounded at a community pharmacy. Clin Infect Dis 2006;43:831-7.

9. Mintz L, Mollett GH. Letter: Serratia vertebral osteomyelitis in narcotic addicts. Ann Intern Med 1975;83:668-9.

10. Peeters A, Vandercam B, Sindic CJ, Hantson P, Mahieu P. Community-acquired Serratia marcescens meningitis. J Infect 1997;35:303-4.
11. Prosser BJ, Horton J. A rare case of serratia sepsis and spontaneous abortion. N Engl J Med 2003;348:668-9.

12. Pitout JD, Gregson DB, Church DL, Laupland KB. Populationbased laboratory surveillance for AmpC beta-lactamase-producing Escherichia coli, Calgary. Emerg Infect Dis 2007;13:443-8.

13. Pitout JD, Hanson ND, Church DL, Laupland KB. Populationbased laboratory surveillance for Escherichia coli-producing extended-spectrum beta-lactamases: Importance of community isolates with blaCTX-M genes. Clin Infect Dis 2004:38:1736-41.

14. Pitout JD, Nordmann P, Laupland KB, Poirel L. Emergence of Enterobacteriaceae producing extended-spectrum beta-lactamases (ESBLs) in the community. J Antimicrob Chemother 2005;56:52-9. 


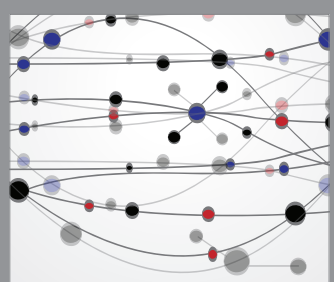

The Scientific World Journal
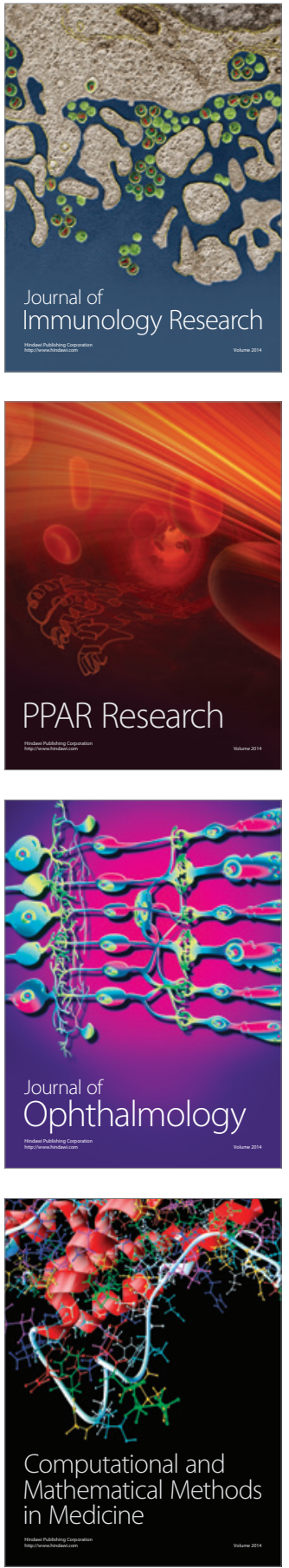

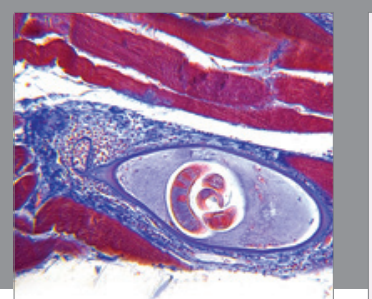

Gastroenterology Research and Practice

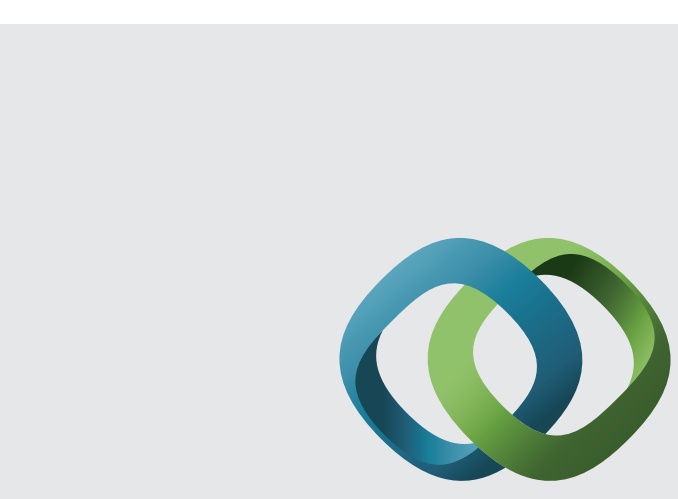

\section{Hindawi}

Submit your manuscripts at

http://www.hindawi.com
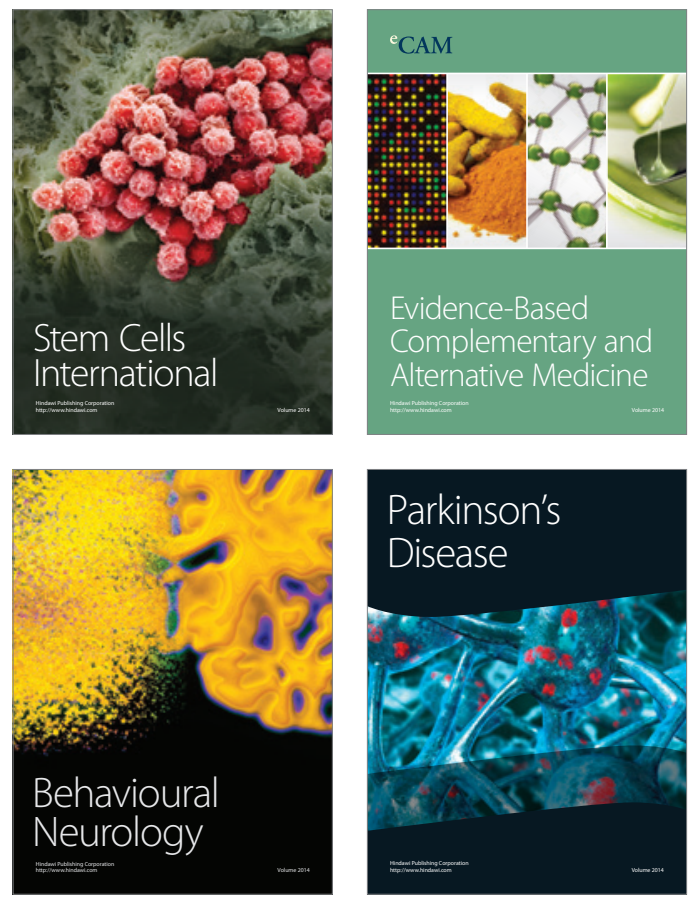
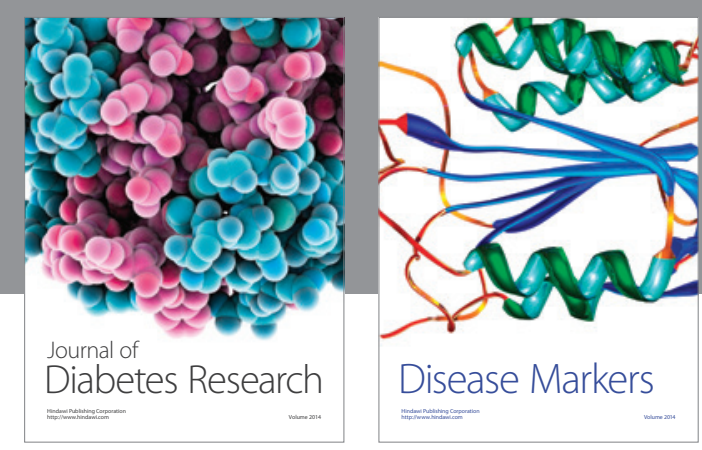

Disease Markers
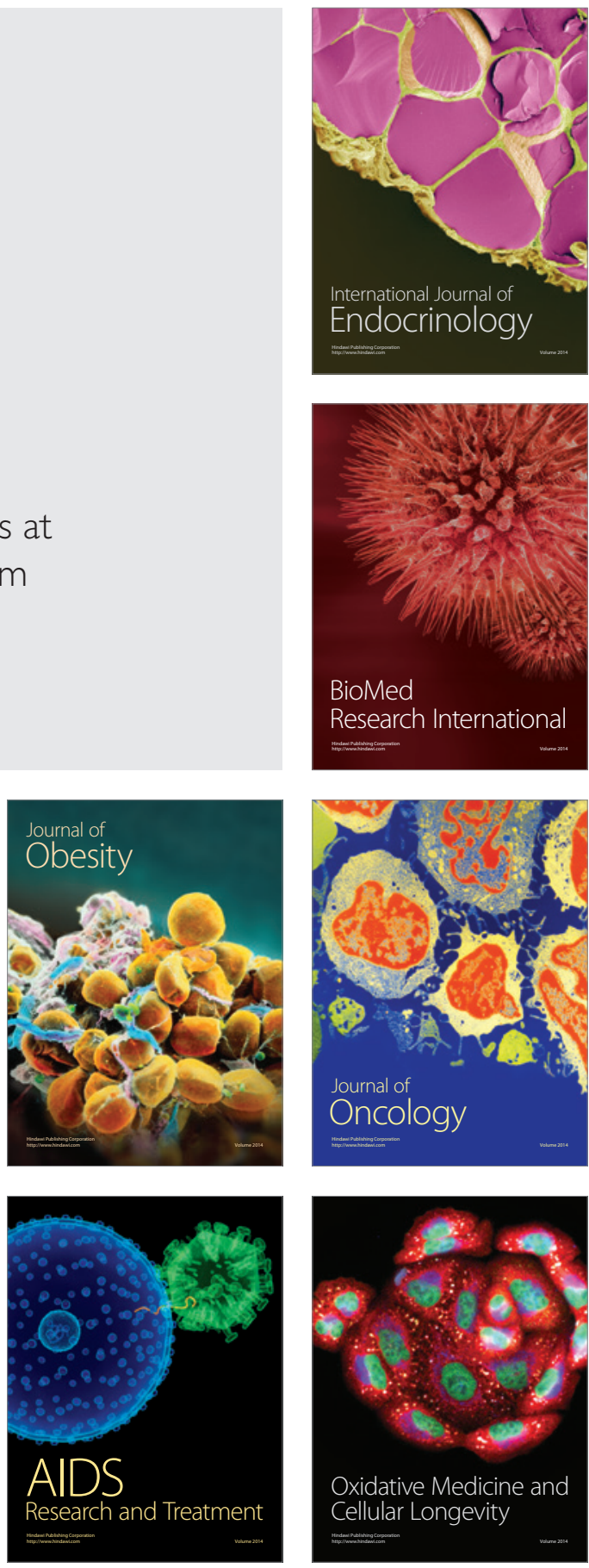